\title{
An Integrated Motor Drive with Enhanced Power Density Using Modular Converter Structure
}

\author{
$1^{\text {st }}$ Abdalla Hussein Mohamed \\ Electromechanical, Systems and Metal Engineering \\ Ghent University \\ Gent, Belgium \\ Flanders Make@UGent - core lab EEDT-MP \\ Abdalla.Mohamed@Ugent.be
}

$3^{\text {rd }}$ Peter Sergeant

Electromechanical, Systems and Metal Engineering

Ghent University

Gent, Belgium

Flanders Make@UGent - core lab EEDT-MP

Peter.Sergeant@Ugent.be

\author{
$2^{\text {nd }}$ Hendrik Vansompel \\ Electromechanical, Systems and Metal Engineering \\ Ghent University \\ Gent, Belgium \\ Flanders Make@UGent - core lab EEDT-MP \\ Hendrik.Vansompel@Ugent.be
}

\begin{abstract}
In this paper, an integrated motor drive with modular converter structure is analysed with different number of converter modules per phase. The integration concept is realized by designing a housing structure with a flat outer surface and a circular inner surface with a cooling channel in between. The converter modules are mounted on the outer flat surface and the stator components are attached to the inner surface. This integration topology is applied on a fifteen stator coil concentrated winding permanent magnet axial flux machine. The converter modules are implemented as half-bridge inverter using Gallium Nitride (GaN) technology. The cooling structure is optimized using computational fluid dynamics (CFD) simulations. The maximum thermally safe current that can be injected by one inverter module is computed. The maximum winding current is also calculated. Parallel connection of the inverter modules is suggested to maximize the thermal utilization of the windings while keeping the inverter switches junction temperature under the rated value. The CFD based computations are validated with experimental measurements.
\end{abstract}

Index Terms-Integrated Drives, Wide Bandgap devices, Motor Drives, Thermal Modelling, circumscribing polygon, Modular Drives, Axial flux machines, Power density, GaN.

\section{INTRODUCTION}

Integration of power converters and electrical machines has many advantages. The combination of the inverter and the machine into the same housing cooled with the same structure reduces the overall weight and volume of the drive [1], [2]. The elimination of the long cables connecting the inverter to the machine windings also contributes to the reduction of the weight and the volume of the drive besides the reduction of the electromagnetic interference (EMI) generated by the drive [3], [4]. The converter modularity adds more advantages to the integrated drives such as, reduced thermal and electrical stresses on the converter modules, the reduced space occupied by each module [5], [6] and the possibility to scale the drive power by parallel connection of converter modules.
The most challenging aspects in the design of the integrated motor drives (IMD) are the shared thermal management of the machine and the converter [7], [8] and the small space available for the converter modules [9]. These challenges can be met by utilizing the wide bandgap (WBG) semiconductor switches especially, the Gallium Nitride $(\mathrm{GaN})$ technology thanks to its low losses and small package size for the same voltage and current ratings compared to Silicon devices [3], [10].

The integrated motor drives can be classified according to the location of the power converter with respect to the machine stator into axially stator mounted (ASM), radially stator mounted (RSM), axially housing mounted (AHM), radially housing mounted (RHM) [2] and circumscribing polygon (CP) integrated drive [11]. In the ASM and RSM, the inverter modules are mounted near to the back iron of the stator while in the AHM and RHM, the inverter modules are mounted in an extended part of the machine housing in the axial or the radial direction.

In the $\mathrm{CP}$, the inverter modules are arranged radially around the circumference of a shared cooling structure with an outer polygon shape in the circumferential direction. In [11], the concept of the circumscribing polygon integration topology is introduced. There, it is shown that the converter switches reach the junction temperature limit while the machine windings remain at low temperature if one converter module controls one phase of the machine. To maximize the thermal utilization of the windings, and hence increasing the output power, the parallel operation of several converter modules per phase is studied in this paper.

The paper is divided as follows: section II gives a brief description for the CP integrated drive studied in this paper. Section III elaborates the design of the GaN based converter module and the optimization of the shared cooling structure. In section IV, the maximum thermally safe winding and inverter 


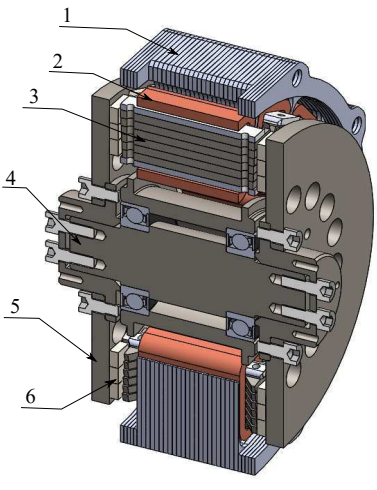

(a)

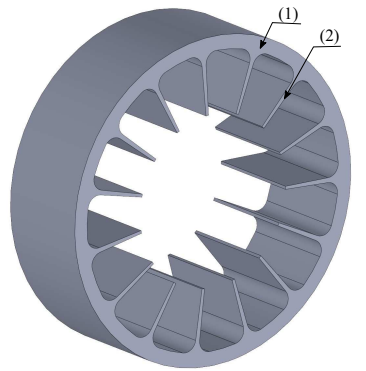

(b)
Fig. 1: Non-integrated YASA axial flux PMSM: (a) Cross-section view of the non-integrated machine: (1) housing, (2) winding, (3) core, (4) shaft, (5) rotor Disc, (6) PMs. (b) Non-integrated YASA housing construction: (1) outer periphery, (2) fins

switches currents are computed along with the possibility of the parallel operation of the modules. In section $\mathrm{V}$, the parallel connection of the inverter modules for maximum thermal utilization of the machine windings is investigated. The experimental results are given in section VI. The conclusions are reported in section VII.

\section{Mechanical Structure of the CP Integrated DRIVE}

Fig. 1 (a) shows the construction of the non-integrated yokeless and segmented armature (YASA) axial flux permanent magnet synchronous machine (PMSM) considered for illustration of the $\mathrm{CP}$ integration concept. The stator has fifteen modules. Each module (see Fig. 2 (a)) consists of a coil with a number of turns wound around a silicon steel core. The fifteen coils are arranged circumferentially and bonded together with the housing to form the concentrated winding structure of the machine. The machine has two rotor disks with surface mounted permanent magnets (PMs) as shown in Fig. 2 (b).

The major part of the heat dissipated by the stator transfers to the ambient through the housing structure shown in Fig. 1 (b) [12]. The rest of the stator heat transfers partly to the airgap by the ventilation action of the rotor discs [13] and partly to the ambient through the shaft [14]. The heat generated by the rotor PMs gets evacuated in the air-gap.

The housing shown in Fig. 1 (b) is re-designed to mechanically house the driving half-bridge converter modules and cool them together with the stator of the machine. The outer circular cross-section of the housing is replaced by its circumscribing polygon with number of sides equal to the number of the stator modules. In the case study of this paper, the number of sides is fifteen. Fig. 3 (b) shows the geometry of the redesigned stator housing. An outer flat surface for mounting the half bridge modules is created. An axial cooling channel is created between the inner and the outer surfaces of the housing. This cooling channel decouples the heat generated by the converter modules and the stator modules. An overview of

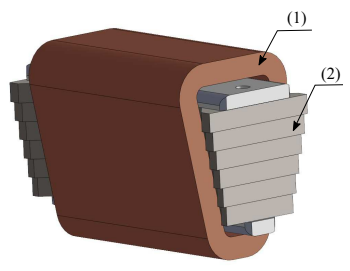

(a)

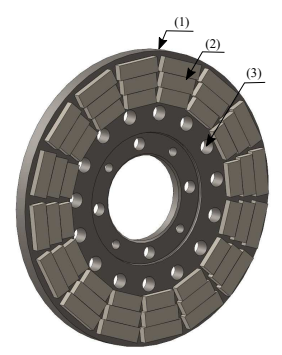

(b)
Fig. 2: YASA stator and rotor elements (a) stator coil construction: (1) winding, (2) core, (b) rotor construction: (1) rotor backiron, (2) magnets, (3) ventilation holes

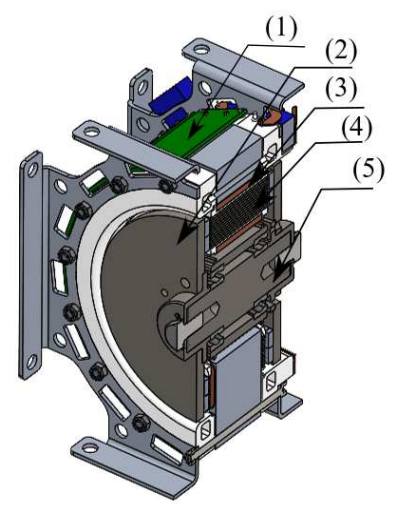

(a)

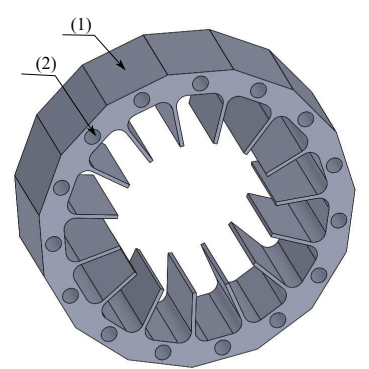

(b)
Fig. 3: The integrated YASA drive: (a) The full drive, (1) the converter module, (2) the rotor disk, (3) the windings, (4) the core, (5) shaft. (b) The re-designed housing: (1) flat surface, (2) decoupling cooling channel

TABLE I: The key geometrical parameters of the YASA machine

\begin{tabular}{cc}
\hline \hline Quantity & Value \\
\hline \# pole pairs & 8 \\
\# Slots & 15 \\
Axial stack length $L_{a}(\mathrm{~mm})$ & 60 \\
Outer diameter $D_{o}(\mathrm{~mm})$ & 190 \\
\hline \hline
\end{tabular}

the full integrated machine is shown in Fig. 3 (a). More details about this integration topology can be found in [11].

The key geometrical parameters of the YASA machine are included in Table I.

The dimension of the inverter module printed circuit board (PCB) in the axial direction is equivalent to $L_{a}$ of the machine. The dimension in the circumferential direction $\left(L_{c}\right)$ can be calculated from (1). The module dimensions for the case study in this paper should be $60 \times 40 \mathrm{~mm}^{2}$.

$$
L_{c}=D_{o} \tan \left(\frac{180^{\circ}}{n}\right)
$$

where, $n$ is the number of the stator modules. 


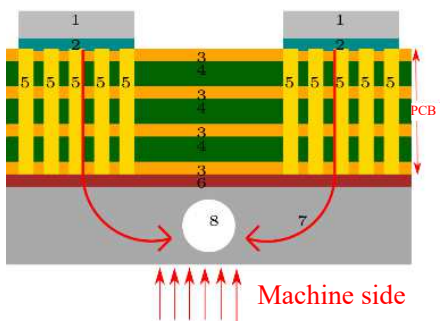

Fig. 4: Illustration of the thermal resistances in the path of the heat generated by the switches: (1) switch junction, (2) switch case, (3) PCB copper layers, (4) PCB laminate (FR4), (5) thermal vias, (6) TIM, (7) shared cooling structure, (8) cooling channel.

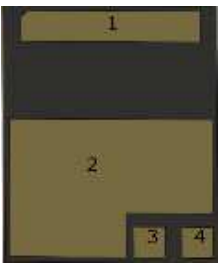

(a)

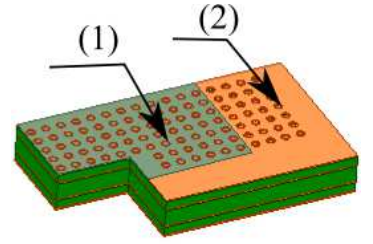

(b)
Fig. 5: The switch package outline and the thermal vias: (a)The GS66508B GaN switch package: (1) drain, (2) source (thermal pad), (3) source2, (4) gate. (b) The inverter module PCB beneath the switch: (1) the thermal vias beneath the switch case, (2) thermal vias beyond the switch case

\section{HALF-BRidge InVERTer Module Design}

The design of the inverter module involves the determination of the dimensions, the selection of the switch with the proper package size and electrical ratings and the design of the inverter module PCB. The GaN switch (GS66508B) is chosen for the implementation of the inverter module. This switch is selected for two reasons: the first one is its low losses indicated by its small figure of merit $\left(F O M=R_{d s} \times Q_{g}=\right.$ $2.9 \times 10^{-10} \Omega$.C $)$ and the zero reverse recovery charge $\left(Q_{r r}\right)$ indicating zero switching losses in the reverse conduction path. The second reason is its small package size $\left(7.1 \times 8.5 \mathrm{~mm}^{2}\right)$.

For optimal thermal performance of the switches, the thermal resistance from the junction of the switches to the cooling fluid should be minimized. Fig. 4 shows the different thermal resistances from the junction of the switches to the cooling fluid. These thermal resistances are the junction to case $\left(R_{j c}\right)$, the PCB thermal resistance $\left(R_{p c b}\right)$, the thermal interface material (TIM) thermal resistance $\left(R_{\text {TIM }}\right)$ and the cooling structure thermal resistance $\left(R_{t h c o o l}\right)$. The $R_{p c b}$ can be minimized by utilizing thermal vias and $R_{\text {thcool }}$ can be minimized by optimal design of the cooling channel radius $(R)$.

The $R_{p c b}$ is minimized by populating the thermal vias shown in Fig. 5 (b) underneath the thermal pad of the selected switch. The thermal pad of the switch is shown in Fig. 5 (a) (Pin (2)). Compared to the case without thermal vias, the $R_{p c b}$ is reduced from $62^{\circ} \mathrm{C} / \mathrm{W}$ to $2.1^{\circ} \mathrm{C} / \mathrm{W}$ [15].

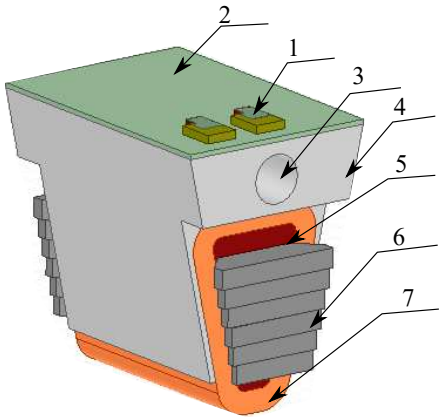

Fig. 6: One integrated module geometry: (1) the inverter switches, (2) the thermal interface material (TIM), (3) the cooling channel, (4) the shared cooling structure, (5) the impregnation epoxy resin, (6) the core laminations, (7) the windings

TABLE II: The thermal properties of the materials of one module

\begin{tabular}{lllll}
\hline \hline \multirow{2}{*}{ Module part } & \multicolumn{1}{c}{ Material } & $\rho\left(\mathrm{kg} / \mathrm{m}^{3}\right)$ & $C_{p}(\mathrm{~J} / \mathrm{kg} \cdot \mathrm{k})$ & $K(\mathrm{~W} / \mathrm{m} . \mathrm{K})$ \\
\hline Winding & Copper & 8890 & 392 & 385 \\
Core & silicon steel & 7650 & 490 & 40 \\
Housing & Aluminum & 2712 & 896 & 167 \\
Impregnation & epoxy & 1540 & 600 & 0.4 \\
TIM & silicon compound & 2750 & 710 & 4.4 \\
\hline \hline
\end{tabular}

To assess the influence of the cooling channel radius and the flow rate of the water on the inner wall convection coefficient and the temperature of the switches,a CFD model is built for one integrated module. The geometry of one integrated module is shown in Fig. 6. The thermal properties of the different materials are given in Table II.

The CFD model is run for different channel radii and different flow rates assuming $5 \mathrm{~W}$ loss per switch, $50 \mathrm{~W}$ winding loss per coil, $50 \mathrm{~W}$ core loss per module and $20^{\circ} \mathrm{C}$ water inlet temperature. The result is reported in Fig. 7 (left) and Fig. 7 (right) respectively for the convection coefficient and the switch case temperature. As can be seen from Fig. 7 , the smallest channel radius $(2 \mathrm{~mm})$ results in the highest convection coefficient and the smallest switch case temperature at the same flow rate due to the higher fluid speed at the smaller channel radius. The convection coefficient increases and the temperature decreases with the flow rate.

Fig. 8 shows the implemented GaN based half-bridge module.

\section{MAXimum Thermally SAFE Winding AND Switch CURRENT}

The maximum current that can be injected in the winding without exceeding the insulation thermal limit is evaluated using the CFD model. The following steps are performed to calculate the maximum winding current:

- At $1 \mathrm{LPM}$ water flow rate and $25^{\circ} \mathrm{C}$ water inlet temperature, the winding loss is increased until the winding hotspot temperature reaches $115^{\circ} \mathrm{C}$ (the extra room until reaching the winding insulation rated temperature is left for the core loss). 

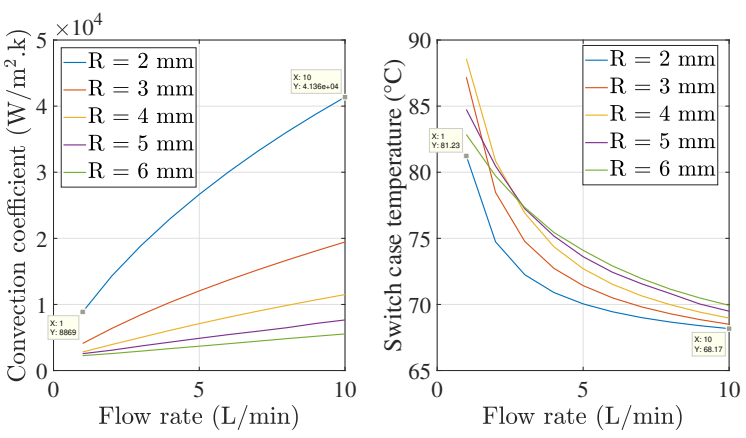

Fig. 7: Effect of the channel radius and flow rate on the convection coefficient (left) and the switch case temperature (right)

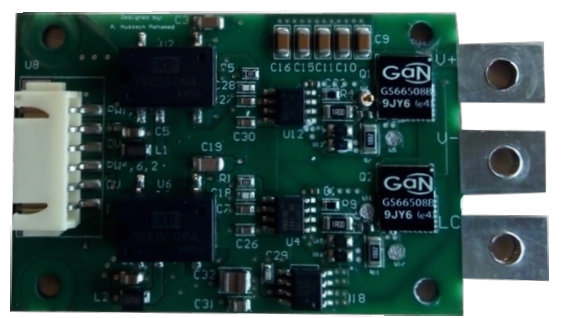

Fig. 8: The implemented GaN based half-bridge inverter module

- The winding loss value resulting from step 1 is recorded and the average winding temperature as well.

- The winding resistance is computed using (2) and the winding current is computed from (3).

- The core loss is computed from [16] and injected in the CFD model to evaluate the new hotspot temperature. If the hotspot temperature is lower than the limit of the insulation $\left(130^{\circ} \mathrm{C}\right.$ for class $\left.\mathrm{B}\right)$, the computed current is recorded. If not, the current is decreased, the losses are computed and the new hotspot temperature until reaching a value lower than the rated winding temperature.

$$
R_{\text {coilhot }}=R_{o}\left(1+\alpha\left(T_{w d g}-T_{o}\right)\right)
$$

where, $R_{o}=138.9 \mathrm{~m} \Omega$ is the winding resistance at $25^{\circ} \mathrm{C}, \alpha$ is the resistance temperature coefficient which equals $0.393 \% /{ }^{\circ} \mathrm{C}$ for copper, $T_{w d g}$ is the average winding temperature.

$$
I_{w d g}=\sqrt{\left(\frac{P_{\text {losscoil }}}{R_{\text {coilhot }}}\right)}
$$

where, $I_{w d g}$ is the maximum possible winding current, $P_{\text {losscoil }}$ is the maximum coil loss computed by the CFD.

Applying the above steps results in a hotspot winding temperature of $115^{\circ} \mathrm{C}$ at $73 \mathrm{~W}$ coil loss and zero core loss, this result is shown in Fig. 9 (a). The average coil temperature is $101.5^{\circ} \mathrm{C}$ and the corresponding coil resistance is $186.5 \mathrm{~m} \Omega$. The resulting winding current is $20 \mathrm{~A} \mathrm{rms}$. The core loss per module is computed and amounts to 9 W. Fig. 9 (b) shows the module temperature distribution with the core loss considered. The winding hot spot temperature is $127^{\circ} \mathrm{C}$ which is still affordable by insulation class $\mathrm{B}$ and higher.

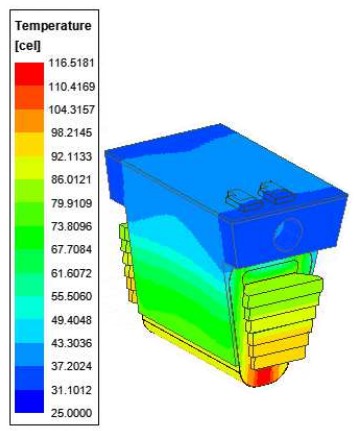

(a)

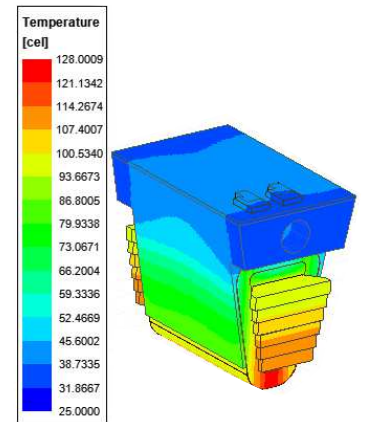

(b)
Fig. 9: The module temperature distribution (a) in case of $73 \mathrm{~W}$ winding loss per module and no core loss (b) in case of 73 $\mathrm{W}$ winding loss per module and $9 \mathrm{~W}$ core loss

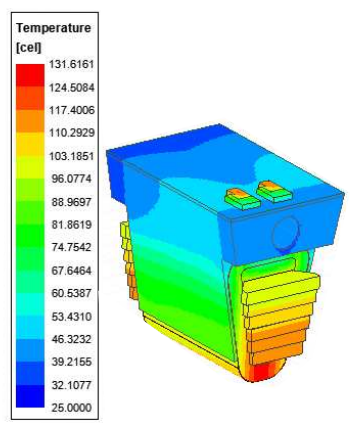

Fig. 10: Temperature distribution over one module considering 8.5 $\mathrm{W}$ switch loss, $73 \mathrm{~W}$ per module winding loss and $9 \mathrm{~W}$ per module core loss

The maximum winding current that can be injected with one inverter module without exceeding the rated junction temperature $\left(150^{\circ} \mathrm{C}\right)$ of the switch is computed as follows:

- The switch loss that results in $115^{\circ} \mathrm{C}$ junction temperature is computed using the CFD model.

- From the switch loss versus temperature model developed in [9], the peak winding current that results in the switch loss in step 1 is calculated.

Applying the above steps results in $115^{\circ} \mathrm{C}$ junction temperature at $8.5 \mathrm{~W}$ switch loss. The temperature distribution over one integrated module including the switches is shown in Fig. 10. From Fig. 11, the peak line current that can be injected by one inverter module is $14 \mathrm{~A}$ which corresponds to $9.8 \mathrm{~A}$ rms.

\section{Parallel Connection of Inverter Modules}

The fifteen stator modules YASA machine studied in this paper can operate as three-phase by connecting five-stator modules in series to form one phase (see Fig. 12 (a)) or fivephase machine by connecting three-stator modules in series to form one phase (see Fig. 12 (b)). Since the shared cooling structure can accommodate up to fifteen-inverter modules, up to five-modules per phase can be used in case of three-phase operation as shown in Fig. 13 (a) and up to three-modules per 


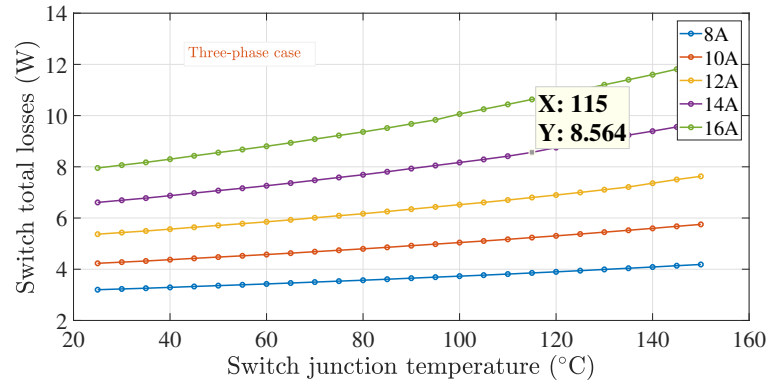

Fig. 11: Switch loss versus temperature at different winding currents

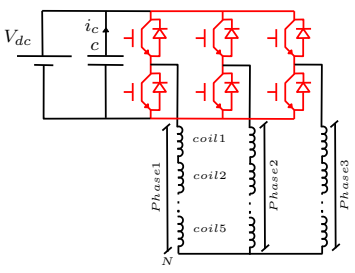

(a)

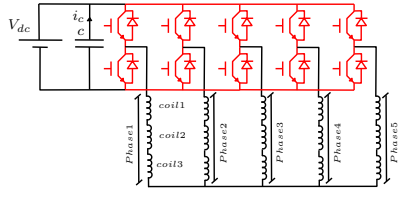

(b)
Fig. 12: Stator modules connection (a) in case of three-phase operation, (b) in case of five-modules connection

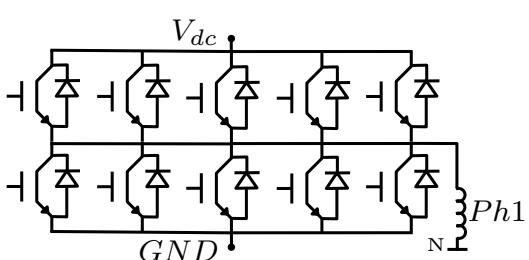

(a)

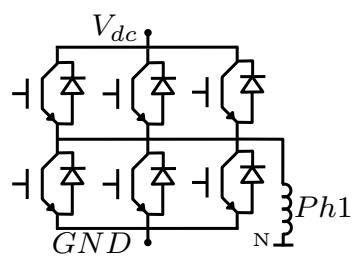

(b)
Fig. 13: Possible number of parallel connected converter modules per phase in case of (a) Three-phase operation, (b) Five-phase operation

phase can be used in case of five-phase operation as shown in Fig. 13 (b).

As discussed in section IV, the windings can thermally afford up to $20 \mathrm{~A}$ rms while the converter module can only inject up to $9.8 \mathrm{~A}$ rms winding current. For maximum thermal utilization of the windings without exceeding the rated junction temperature of the switches, each phase can be supplied from two-modules connected in parallel (up to 19.6 A winding current) or three-modules working at alleviated junction temperature (i.e. $<115^{\circ} \mathrm{C}$ )

\section{EXPERIMENTAL RESULTS}

The setup shown in Fig. 14 is built to validate the simulation results and to show the effectiveness of the parallel operation of the modules.

\section{A. Modelling validation}

To validate the CFD modelling introduced in section IV, The winding hot-spot, the core and the switch temperatures are recorded at $1 \mathrm{LPM}, 25^{\circ}$ water inlet temperature, $73 \mathrm{~W}$ coil loss and $8.5 \mathrm{~W}$ switch loss. The results are shown in Fig. 15 (a), (b) and Fig. 16 for the core, the winding hot-spot and the

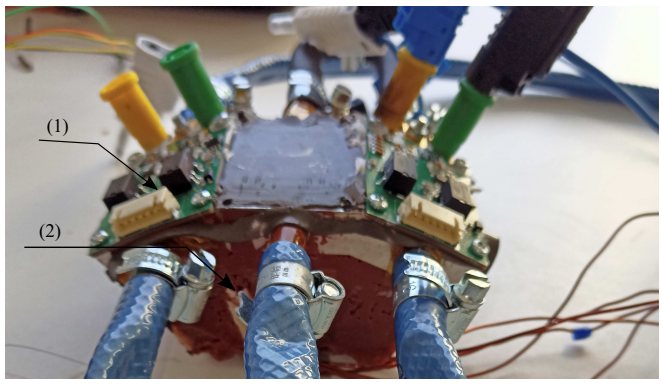

Fig. 14: A three-teeth integrated setup for validation of the parallel operation: (1) Converter module, (2) Motor teeth

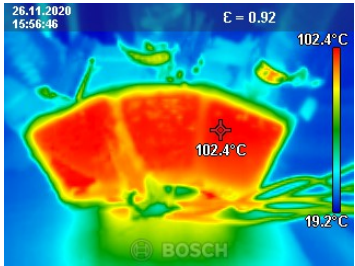

(a)

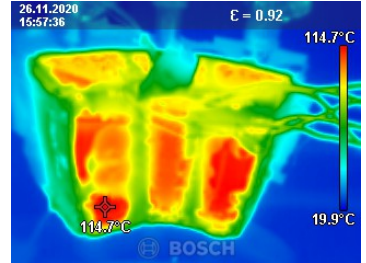

(b)
Fig. 15: The CFD model validation at $1 \mathrm{LPM}, 73 \mathrm{~W}$ per coil loss, $8.5 \mathrm{~W}$ switch loss and $25{ }^{\circ} \mathrm{C}$ inlet water temperature: (a) core temperature, (b) winding hot-spot temperature

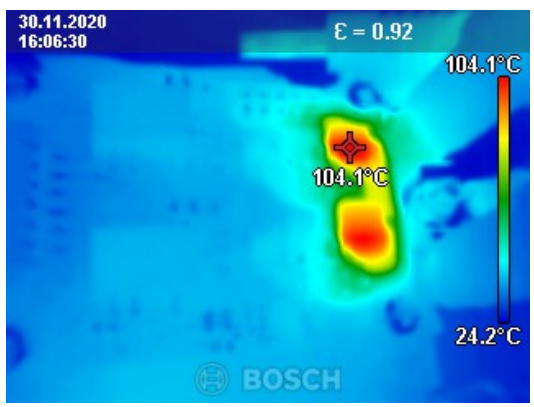

Fig. 16: The measured switch temperature at $1 \mathrm{LPM}, 73 \mathrm{~W}$ per coil loss, $8.5 \mathrm{~W}$ switch loss and $25^{\circ} \mathrm{C}$ inlet water temperature for CFD model validation

switch temperatures respectively. The temperature distribution and values are in good agreement with the CFD modelling presented in Fig. 9 and Fig. 10.

\section{B. Parallel operation assessment}

To show the effectiveness of the parallel operation of the converter modules. The converter modules and the windings are connected as shown in Fig. 17 (a) for a single converter connected in series with the three-coils and Fig. 17 (b) for twoconverters in parallel series connected with the three-coils.

The injected winding current is 9.5 $\mathrm{A}$ and 18.2 $\mathrm{A}$ for the case of one module in series with the windings and two modules in parallel respectively. The water flow rate is 1 LPM and the inlet temperature is $25^{\circ} \mathrm{C}$. The winding hot-spot temperature and the switches temperature are reported in Fig. 18 and Fig. 19 respectively for both cases. It can be noticed that almost double the windings current can be injected in case of parallel operation without much change in the junction 




(a)

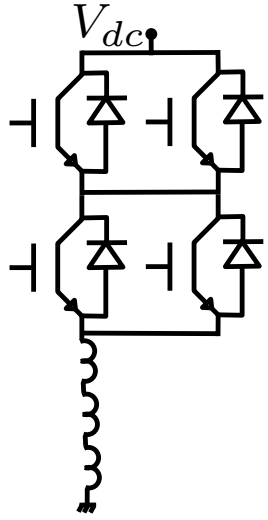

(b)
Fig. 17: Converter modules and stator coils connection in case of (a) One-module in series with the windings, (b) Two-modules in parallel in series with the windings

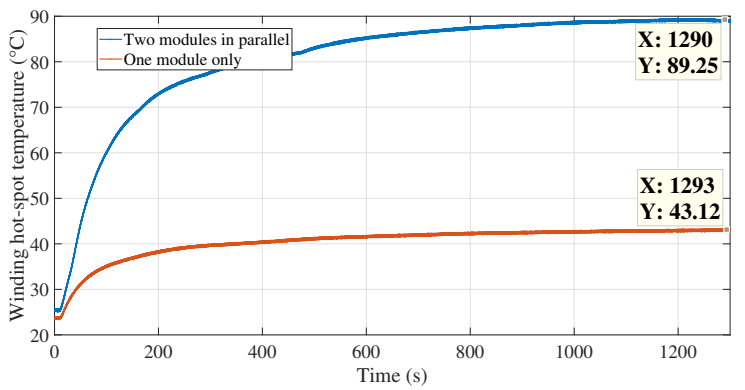

Fig. 18: The measured winding hot-spot temperature in case of one converter module and two-modules in parallel at $9.5 \mathrm{~A}$ and $18.2 \mathrm{~A}$

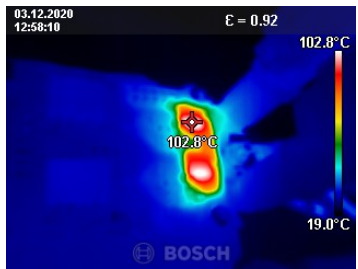

(a)



(b)
Fig. 19: The measured switch temperature in case of (a) one module supplying 9.5 A winding current and (b) two-modules in parallel supplying 18.2 A winding current

temperature of the switches proving the effectiveness of the suggested parallel operation of the converter modules.

\section{CONCLUSION}

An integrated drive with shared cooling for the power converter and the electrical machine implemented using modular converter structure is presented in this paper. A CFD model is built for one integrated module and validated by experimental measurements. The converter switches thermal limit makes it possible to nject only half of the current that can be thermally tolerated by the windings. This limitation on the converter current reduces the maximum power that can obtained from the machine. To overcome this limitation, the parallel operation of the converter modules is suggested in this paper. The current that can be injected with the parallel operation of the converter can be doubled, tripled and so on depending on the number of modules in parallel without exceeding the thermal limit of the switches. The effectiveness of the parallel operation is validated by experimental measurements.

\section{REFERENCES}

[1] T. M. Jahns and H. Dai, "The Past , Present , and Future of Power Electronics Integration Technology in Motor Drives," CPSS Transactions on Power Electronics and Applications, vol. 2, no. 3, pp. 197-216, 2017.

[2] W. Lee, S. Li, D. Han, B. Sarlioglu, T. A. Minav, and M. Pietola, "A Review of Integrated Motor Drive and Wide-Bandgap Power Electronics for High-Performance Electro-Hydrostatic Actuators," IEEE Transactions on Transportation Electrification, vol. 4, no. 3, pp. 684-693, 2018.

[3] R. Abebe, G. Vakil, G. L. Calzo, T. Cox, S. Lambert, M. Johnson, C. Gerada, and B. Mecrow, "Integrated motor drives: State of the art and future trends," IET Electric Power Applications, vol. 10, no. 8, pp. 757-771, 2016.

[4] M. Maerz, E. Schimanek, and M. Billmann, "Towards an Integrated Drive for Hybrid Traction," no. September, pp. 3-7, 2008.

[5] J. Wang, Y. Li, and Y. Han, "Evaluation and design for an integrated modular motor drive (IMMD) with GaN devices," 2013 IEEE Energy Conversion Congress and Exposition, ECCE 2013, no. Immd, pp. 43184325, 2013.

[6] T. M. Jahns, "Hardware Integratio on for an Integrated Mod dular Motor Drive Incl luding Distributed Contr rol," pp. 4881-4887, 2014.

[7] M. Maerz, M. Poech, E. Schimanek, and A. Schletz, "Mechatronic Integration into the Hybrid Powertrain-The Thermal Challenge," Proc. 1th International Conference on Automotive Power Electronics (APE), no. June, pp. 2-7, 2006. [Online]. Available: http://www.ecpe.org/download/publications/Paper_Maerz_APE2006.pdf

[8] A. Tenconi, F. Profumo, S. E. Bauer, and M. D. Hennen, "Temperatures evaluation in an integrated motor drive for traction applications," IEEE Transactions on Industrial Electronics, vol. 55, no. 10, pp. 3619-3626, 2008.

[9] A. H. Mohamed, H. Vansompel, and P. Sergeant, "Design of a circumscribing polygon wide bandgap based integrated modular motor drive topology with thermally decoupled windings and power converters," 2020 22nd European Conference on Power Electronics and Applications, EPE 2020 ECCE Europe, pp. 1-9, 2020.

[10] J. Wang, Y. Li, and Y. Han, "Integrated Modular Motor Drive Design With GaN Power FETs," IEEE Transactions on Industry Applications, vol. 51, no. 4, pp. 3198-3207, 2015.

[11] A. H. Mohamed, H. Vansompel, and P. Sergeant, "An Integrated Modular Motor Drive with Shared Cooling for Axial Flux Motor Drives," IEEE Transactions on Industrial Electronics, pp. 1-1, oct 2020.

[12] H. Vansompel, P. Leijnen, and P. Sergeant, "Multiphysics Analysis of a Stator Construction Method in Yokeless and Segmented Armature Axial Flux PM Machines,' IEEE Transactions on Energy Conversion, vol. 34 no. 1, pp. 139-146, 2019.

[13] A. Mohamed, A. Hemeida, A. Rasekh, H. Vansompel, A. Arkkio, and P. Sergeant, "A 3D Dynamic Lumped Parameter Thermal Network of Air-Cooled YASA Axial Flux Permanent Magnet Synchronous Machine," Energies, vol. 11, no. 4, p. 774, mar 2018. [Online]. Available: https://www.mdpi.com/1996-1073/11/4/774

[14] A. Mohamed, A. Hemeida, H. Vansompel, and P. Sergeant, "Parametric Studies for Combined Convective and Conductive Heat Transfer for YASA Axial Flux Permanent Magnet Synchronous Machines," Energies, vol. 11, no. 11, p. 2983, nov 2018. [Online]. Available: http://www.mdpi.com/1996-1073/11/11/2983

[15] A. H. Mohamed, H. Vansompel, and P. Sergeant, "Electro-thermal Design of a Discrete GaN Based Converter for Integrated Modular Motor Drives," IEEE Journal of Emerging and Selected Topics in Power Electronics, pp. 1-1, feb 2021.

[16] A. Hemeida and P. Sergeant, "Analytical modeling of surface PMSM using a combined solution of Maxwell-s equations and magnetic equivalent circuit," IEEE Transactions on Magnetics, vol. 50, no. 12, dec 2014. 